\title{
Evaluasi Kinerja Wireless 802.11N untuk E- Learning
}

\author{
Apri Siswanto \\ Program Studi Teknik Informatika, Fakultas Teknik, Universitas Islam Riau \\ e-mail: aprisiswanto@eng.uir.ac.id
}

\begin{abstract}
This research is the evaluation on the performance of the Wireless Local Area Network (WLAN) 802.11n, implemented in the Department of Engineering, Universitas Islam Riau. The research in the wake server E Learning and will be accessed using the Wireless LAN 802.11n. This simulation uses Riverbed Software Modeler and studies a simulation to estimate the number of web user clients and other network applications that could be supported by the Wireless LAN 802.11 n to provide certain network load. The simulation produced a display that IEEE 802.11n WLAN can support up more than 100 client users e learning with web browsing activity.
\end{abstract}

Keywords : WLAN, Riverbed Modeler, 802.11n, e-Learing

\begin{abstract}
Abstrak
Penelitian ini merupakan evaluasi kinerja tentang wireless LAN (WLAN) 802.11N yang diimplementasikan dalam suatu lingkungan fakultas. Dalam penelitian ini di bangun server E Learning dan akan di akses menggunakan Wireless LAN 802.11N. Simulasi ini menggunakan Perangkat Lunak Riverbed Modeler. Penelitian ini merupakan sebuah simulasi untuk memperkirakan jumlah klien pengguna web dan aplikasi jaringan lainnya yang bisa didukung oleh Wireless LAN 802.11N dengan memberikan beban jaringan tertentu. Pada penelitian ini simulasi menghasilkan tampilan bahwa WLAN IEEE 802.11N bisa mendukung sampai lebih dari 100 klien pengguna e learning dengan aktifitas web browsing.
\end{abstract}

Kata Kunci- Wireless Local Area Network (WLAN), HTTP, E Learning, Riverbed Modeler, IEEE $802.11 \mathrm{~N}$

\section{PENDAHULUAN}

Perkembangan teknologi informasi atau yang dikenal dengan Information and Technology (IT) sudah mempengaruhi berbagai aspek kehidupan masyarakat. Pada bidang pendidikan terutama di perguruan tinggi, salah satu dampak yang muncul ialah kegiatan belajar dan mengajar dapat dilaksanakan dengan konsep e- learning. Menurut Hartley [1] e-learning adalah suatu jenis belajar mengajar yang memungkinkan tersampaikannya bahan ajar ke siswa dengan menggunakan media Internet, Intranet atau media jaringan komputer lain.

Sistem e-learning telah banyak diaplikasikan oleh masyarakat dunia, dan menjadi tren pendidikan berbasis TIK. Di Indonesia melalui Departemen Pendidikan Nasional (Depdiknas) juga telah mengadaptasi perkembangan model pembelajaran tersebut yang dituangkan dalam Rencana Strategis Departemen Pendidikan Nasional (Renstra Depdiknas), yang telah mencantumkan bahwa pendidikan harus selalu melakukan adaptasi dan penyesuaian dengan gerak perkembangan ilmu pengetahuan modern dan 
inovasi teknologi maju, sehingga tetap relevan dan kontekstual dengan perkembangan zaman.

Salah satu aspek yang perlu dipertimbangkan dalam perencanaan dan pengembangan e-learning adalah aspek teknologi, dalam hal ini adalah yang menyangkut infrastruktur yang dipergunakan sebagai media untuk proses penyampaian materi pembelajaran. Infrastruktur e-learning dapat berupa personal computer $(P C)$, jaringan komputer, internet dan perlengkapan multimedia. Termasuk didalamnya peralatan teleconference apabila kita memberikan layanan synchronous learning melalui teleconference. Salah satu tren teknologi jaringan saat ini adalah teknologi Wireless LAN. Wireless LAN dapat didefinisikan sebagai sebuah sistem komunikasi data fleksibel yang dapat digunakan untuk menggantikan atau menambah jaringan LAN yang sudah ada untuk memberikan tambahan fungsi dalam konsep jaringan komputer pada umumnya. Fungsi yang ditawarkan dapat berupa konektifitas yang andal sehubungan dengan mobilitas user [2].

Perkembangan wireless LAN saaat ini cukup menjanjikan dan sangat populer di kalangan pendidikan, industri, kesehatan, konstruksi dan lain sebagainya. Selain dapat meningkatkan tingkat produktifitas instansi masing-masing, penggunaan wireless LAN juga merupakan alternatif terbaik solusi jaringan di era global saat ini.

Teknologi Wireleess LAN saat ini mayoritas menggunakan standar IEEE 802.11 $\mathrm{a} / \mathrm{b} / \mathrm{g} / \mathrm{n}$ [3]. Standar yang akan digunakan dalam penelitian ini adalah $802.11 \mathrm{n}$. Untuk dapat memberikan layanan yang memuaskan kepada pengguna, maka kinerja jaringan wireless LAN 802.11n harus berada pada kondisi yang baik. Kinerja jaringan dikatakan baik apabila jaringan berada dalam kondisi stabil serta dapat memberikan pelayanan yang baik terhadap kecepatan transfer data dan bandwidth jaringan. Analisis kinerja jaringan menekankan proses pemantauan dan perhitungan parameter kinerja jaringan pada infrastruktur jaringan seperti kecepatan dan kapasitas transmisi.

Masalah penelitian ini adalah bagaimana kinerja dan performansi wireless $802.11 \mathrm{n}$ jika dipergunakan untuk penerapan aplikasi e-learning berbasis web di suatu lingkungan fakultas, bagaimana pengaruh tingkat transaksi HTTP, wireless delay, throughput yang dicapai dalam lingkungan jaringan wireless e learning dalam suatu lingkungan fakultas dan bagaimana dampak dan pengaruh jaringan terhadap faktor-faktor jumlah klien, dan ukuran besar data yang di akses terhadap e learning [4].

Pada pelaksanaannya penelitian ini dilakukan dengan ruang lingkup masalah hanya membahas konsep dari jaringan wireless 802.11n untuk e learning, E- Learning yang diaplikasikan berbasis web membuat simulasi menggunakan software simulasi jaringan Riverbed Modeler, dan parameter yang digunakan untuk mengukur performansi wireless $802.11 \mathrm{n}$ perhitungan kecepatan transaksi HTTP, dampak dari jumlah pengguna yang mengakses web e learning, ukuran data yang di akses pengguna via web e-learning, wireless access point delay, throughput serta HTTP page response time [5].

Tujuan dari penelitian ini adalah untuk menguji kinerja wireless $802.11 \mathrm{n}$ untuk $e$ learning web base dan membuat sebuah rekomendasi, bahwa standar 802.11n sangat layak digunakan untuk implementasi e learning di lingkungan suatu fakultas.

Penggunaan Wireless LAN semakin populer digunakan di rumah-rumah, kantor, kafe, perpustakaan, bandara, kebun binatang, dan tempat umum lainnya. Dengan perangkat tersebut akan dapat menghubungkan komputer, laptop, PDA dan smartphone ke Internet. Wireless LAN juga dapat digunakan untuk menghubungkan dua atau lebih komputer terdekat berkomunikasi tanpa menggunakan Internet. Standar utama Wireless LAN adalah standar 802.11 [6]. 
Kebutuhan user akan teknologi telekomunikasi dan komunikasi data kini mulai mengarah pada penggunaan teknologi komunikasi yang bisa diakses kapan pun dan dimana pun. Hal ini dapat dilihat dari banyaknya user yang banyak memanfaatkan jaringan wireless untuk melakukan komunikasi. Oleh karena itu mobile data communication mulai dikembangkan untuk mendukung mobilitas user dan faktor fleksibilitas. Maka kini telah dikembangkan suatu LAN berbasis wireless yang dinamakan dengan Wireless LAN [7].

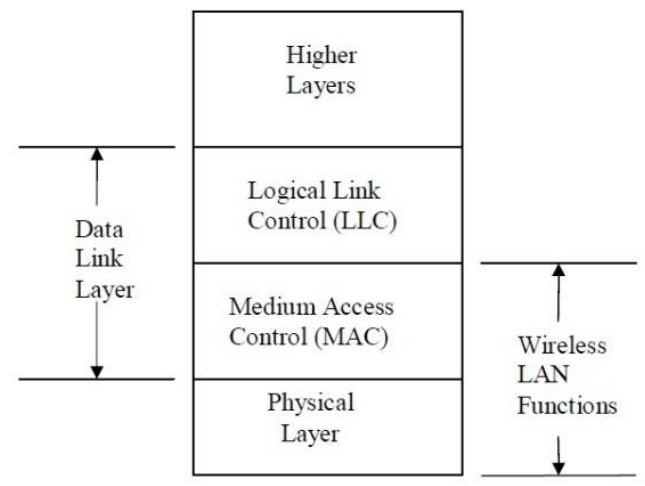

\section{Gambar 1.1 Arsitektur Logika Wireless LAN}

Keunggulan Wireless LAN daripada wired LAN (dengan menggunakan kabel) antara lain adalah:

1. Mobilitas user

2. Hemat dan fleksibel

3. Mudah dalam instalasi dan pemeliharaan

Wireless LAN Pada dasarnya prinsip kerja pada jaringan Wireless LAN sama saja dengan jaringan yang menggunakan ethernet card atau jaringan kabel, perbedaannya yang utama adalah media transmisinya, yaitu melalui udara. Sedangkan pada jaringan ethernet card menggunakan media transmisi melalui kabel. Pada Wireless LAN terdapat dua macam topologi yang biasa digunakan yaitu peer-to-peer atau ad-Hoc dan access point. Sebuah LAN atau jaringan lokal yang media transmisinya melalui kabel udara biasanya menggunakan frekuensi bebas lisensi yaitu pada band 2,4 GHz dan $5 \mathrm{GHz}$ [8].

IEEE 802.11n didasarkan pada standar 802,11 sebelumnya dengan menambahkan multiple-input multiple-output (MIMO) dan $40 \mathrm{MHz}$ ke lapisan saluran fisik (PHY), dan frame agregasi ke MAC layer. MIMO adalah teknologi yang menggunakan beberapa antena untuk menyelesaikan informasi lebih lanjut secara koheren dari pada menggunakan satu antena. Dua manfaat penting MIMO adalah menyediakan keragaman antenna dan spasial multiplexing untuk 802.11n.

Kemampuan lain teknologi MIMO adalah menyediakan Spatial Division Multiplexing (SDM). SDM secara spasial multiplexes beberapa stream data independen, ditransfer secara serentak dalam satu saluran spektral bandwidth. MIMO SDM dapat meningkatkan throughput data seperti jumlah dari pemecahan stream data spatial yang ditingkatkan. Setiap aliran spasial membutuhkan antena yang terpisah baik pada pemancar dan penerima. Di samping itu, teknologi MIMO memerlukan rantai frekuensi radio yang terpisah dan analog-ke-digital converter untuk masingmasing antena MIMO yang merubah biaya pelaksanaan menjadi lebih tinggi dibandingkan dengan sistem nonMIMO [9]. 
Saluran $40 \mathrm{MHz}$ adalah fitur lain yang dimasukkan ke dalam 802.11n yang menggandakan lebar saluran dari $20 \mathrm{MHz}$ di 802.11 PHY sebelumnya untuk mengirimkan data. Hal ini memungkinkan untuk penggandaan kecepatan data PHY melebihi satu saluran $20 \mathrm{MHz}$. Hal ini dapat diaktifkan di $5 \mathrm{GHz}$ mode, atau dalam 2,4 $\mathrm{GHz}$ jika ada pengetahuan yang tidak akan mengganggu beberapa 802.11 lainnya atau sistem non-802.11 (seperti Bluetooth) menggunakan frekuensi yang sama. Arsitektur coupling MIMO dengan saluran bandwidth yang lebih luas menawarkan peningkatan fisik transfer rate melebihi $802.11 \mathrm{a}(5 \mathrm{GHz})$ dan $802.11 \mathrm{~g}(2,4 \mathrm{GHz})$.

Tabel 1. Spesifikasi Wi-fi

\begin{tabular}{|c|c|c|c|c|c|c|}
\hline Release date & Standard & Band $(\mathrm{GHz})$ & Bandwidth (MHz) & Modulation & $\begin{array}{l}\text { Advanced } \\
\text { antenna } \\
\text { technologies }\end{array}$ & $\begin{array}{l}\text { Maximum } \\
\text { data rate }\end{array}$ \\
\hline 1997 & 802.11 & 2.4 & 20 & DSSS, FHSS & N/A & 2 Mbits/s \\
\hline 1999 & $802.11 \mathrm{~b}$ & 2.4 & 20 & DSSS & N/A & 11 Mbits/s \\
\hline 1999 & 802.110 & 5 & 20 & OFDM & N/A & $54 \mathrm{Mbits} / \mathrm{s}$ \\
\hline 2003 & $802.11 \mathrm{~g}$ & 2.4 & 20 & DSSS, OFDM & N/A & 54 Mbits/s \\
\hline 2009 & $802.11 \mathrm{n}$ & 2.4 .5 & 20,40 & OFDM & $\begin{array}{l}\text { MIMO, up to four spotial } \\
\text { streams }\end{array}$ & $600 \mathrm{Mbits} / \mathrm{s}$ \\
\hline 2012 (expected) & 802.11 od & 60 & 2160 & SC, OFDM & Beamforming & $6.76 \mathrm{Gbits} / \mathrm{s}$ \\
\hline 2013 (expected) & 802.11 ac & 5 & $40,80,160$ & OFDM & $\begin{array}{l}\text { MIMO, MU-MIMO, up to } \\
\text { eight spatial streoms }\end{array}$ & $6.93 \mathrm{Gbits} / \mathrm{s}$ \\
\hline
\end{tabular}

Standar IEEE 802.11n dirancang untuk memperbaiki fitur 802.11g dalam jumlah bandwidth yang didukung dengan memanfaatkan beberapa sinyal nirkabel dan antena (disebut MIMO teknologi). Ketika standar ini selesai, koneksi 802.11n harus mendukung kecepatan data yang lebih dari 100 Mbps. 802.11n juga menawarkan jangkauan yang lebih baik dari standar Wi-Fi sebelumnya karena intensitas sinyal meningkat. Peralatan $802.11 \mathrm{n}$ akan kompatibel dengan alat-alat 802.11g. Keunggulan dari 802.11n - kecepatan maksimum serta jangkauan sinyal tercepat dan terbaik; lebih tahan terhadap sinyal interferensi dari sumber-sumber luar.

Kelemahan $802.11 \mathrm{n}$ adalah biaya lebih tinggi dari $802.11 \mathrm{~g}$, penggunaan beberapa sinyal akan sangat mungkin terganggu bila berdekatan dengan $802.11 \mathrm{~b} / \mathrm{g}$ berbasis jaringan.

\section{World Wide Web}

World Wide Web World adalah suatu ruang informasi dimana sumber-sumber daya yang berguna diidentifikasi oleh pengenal global yang disebut Uniform Resource Identifier (URI). Melalui web kita mengakses informasi-informasi global baik berupa teks, gambar, suara, dan lain-lain. Melalui penggunaan aplikasi yang disebut browser, para pengguna dapat mengakses banyak tumpukan informasi yang disimpan dalam server diseluruh dunia [10].

WWW telah menjadi sumber terbesar dari lalu lintas internet. Web telah membuat internet yang tersedia untuk masyarakat dunia dengan menyediakan lokasiindependen, waktu-independen, dan platform-independen untuk akses ke informasi. Web terdiri dari tiga protokol komunikasi: IP, TCP, dan HTTP. Internet Protocol (IP) adalah protokol connectionless lapisan jaringan yang menyediakan pengalamatan global dan 
routing untuk pengiriman datagram di internet. Transmisi Control Protocol (TCP) adalah protokol yang berada pada transport-layer yang menyediakan end-to-end pengiriman data di Internet. Di antara berbagai fungsi, TCP bertanggung jawab untuk kontrol aliran, kontrol kongesti, dan mekanisme pemulihan kesalahan transmisi yang dapat diandalkan untuk menyediakan data antara sumber dan tujuan.

Sedangkan Hyper Text Transfer Protocol (HTTP) adalah suatu protokol yang digunakan untuk mentransfer dokumen/halaman dalam WWW (World Wide Web). Protokol HTTP memeriksa aturan-aturan untuk komunikasi antara browser dan server web. (Ed Tittel, 2004)

HTTP mendefinisikan bagaimana suatu pesan dapat diformat dan dikirimkan dari client ke server atau sebaliknya. HTTP mengatur aksi apa saja yang harus dilakukan oleh web server dan web browser sebagai respon atas perintah-perintah yang ada pada protokol HTTP ini. Pengembangan standar HTTP dilaksanakan oleh Konsorsium World Wide Web (World Wide Web Consortium/W3C) dan juga Internet Engineering Task Force (IETF), yang menghasilkan publikasi beberapa dokumen Request for Comments (RFC), antara lain RFC 2616 yang mendefinisikan tentang HTTP/1.1. (dipublikasikan pada bulan Juni 1999). HTTP merupakan sebuah protokol untuk meminta/menjawab antara klien dan server.

HTTP berjalan pada protocol TCP yaitu pada layer transfer protocol (TCP memiliki beberapa kelebihan dibandingkan dengan UDP). Pertama, HTTP client melakukan inisialisasi terhadap koneksi ke server, jika koneksi stabil maka browser dan server memproses akses melalui jalur TCP menggunakan antarmuka socket masingmasing. Client menggunakan socket interfacenya untuk mengirim HTTP Request dan menerima HTTP Response. Demikian juga dengan server dalam menerima HTTP Request dan mengirim HTTP Response. Ketika Client melakukan HTTP request dan mengirimkan paket via TCP maka HTTP Request sudah lepas dari kendali Client dan masuk menjadi tanggung jawab dari protocol TCP. TCP membangun sebuah jaringan yang dapat dipercaya antara client - server. Server mengirimkan TCP Request tanpa melakukan pencatatan.

Wireless internet dan teknologi wireless LAN 802.11 memiliki peranan penting pada infrastruktur global internet. Salah satu teknologi yang paling populer adalah Wireless LAN yang disebut 802.11n. Teknologi ini termasuk jenis wifi yang menyediakan internet tanpa kabel dengan harga murah pada pelanggannya. Dengan kapasitas hingga $600 \mathrm{Mbps}$ data transmisi pada lapisan fisiknya. Standar IEEE 802.11n didefinisikan sebagai akses channel utama yang digunakan pada lapisan MAC, yang disebut (CSMA/CA).

CSMA/CA menghindari collision dan penggunaan acknowledgements (ACKs). Penggunaan dari acknowledgements, atau ACKs, bekerja dengan cara yang mudah. Ketika pemancar pengirim wireless mengirimkan paket, pemancar penerima mengirim balik ACK sekali setelah penerima paket. Jika pemancar pengirim tidak menerima ACK, pemancar pengirim beranggapan bahwa terjadi collision dan akan mengirimkan kembali data tersebut. CSMA/CA, ditambahkan jumlah ukurannya untuk kontrol data dan digunakan pada wireless LAN, karena diperkirakan akan bertambah 50\% dari jumlah bandwith yang tersedia pada wireless LAN.

\section{E-Learning}

Seiring dengan kebutuhan akan metode dan konsep pembelajaran yang lebih efektif dan efisien, pemanfaatan teknologi informasi untuk pendidikan menjadi tidak terelakkan lagi. Konsep yang kemudian terkenal dengan sebutan eLearning ini membawa 
pengaruh terjadinya proses transformasi pendidikan konvensional ke dalam bentuk digital, baik secara isi (contents) maupun sistemnya.

Darin E. Hartley mengatakan bahwa e learning adalah suatu jenis belajar mengajar yang memungkinkan tersampaikannya bahan ajar ke siswa dengan menggunakan media internet, intranet atau media jaringan komputer lain. Saat ini konsep $e$ learning sudah banyak diterima oleh masyarakat dunia, terbukti dengan maraknya implementasi e learning di lembaga pendidikan (sekolah, training dan universitas) maupun industri (Cisco Systems, IBM, HP, Oracle, dsb).

John Chambers yang merupakan CEO dari perusahaan Cisco Systems mengatakan bahwa aplikasi dalam dunia pendidikan termasuk e-learning didalamnya akan menjadi "killer application" yang sangat berpengaruh di era-era ke depan. Departemen perdagangan dan departemen pendidikan Amerika Serikat bahkan bersamasama mencanangkan Visi 2020 berhubungan dengan konsep pendidikan berbasis teknologi informasi (e-learning). Konsep e-learning semakin berkembang karena memiliki banyak keuntungan dibandingkan sistem konvensional.

Salah satu penerapan e-learning adalah web e-learning. Kinerja keseluruhan dari web e-learning tergantung pada perilaku client web e-learning, server web $e$ learning, dan jaringan di antara web dan client. Tantangan utama dalam konteks internet wireless adalah karakteristik dari saluran wireless. Komunikasi melalui saluran wireless sering mengalami bandwidth yang terbatas, tingkat kesalahan yang tinggi, dan gangguan dari pengguna lain pada saluran yang bersamaan.

Parameter Kinerja Jaringan Wireless 802.11n untuk e learning adalah :

1. DELAY

End to end delay adalah waktu yang diperlukan oleh suatu paket data yang berasal dari source node hingga mencapai destination node. End to end delay secara tidak langsung berhubungan dengan kecepatan transfer data suatu jaringan.

2. THROUGHPUT

Throughput adalah jumlah rata-rata paket yang sukses diterima atau dikirimkan oleh saluran penerima atau pemancar per detik. Throughput merupakan salah satu parameter yang menunjukkan kinerja dari suatu sistem komunikasi

\section{METODE PENELITIAN}

Dalam penelitian digunakan metode penelitian tindakan atau action research yang meliputi pengukuran parameter QoS yaitu Bandwidth, Delay dan Packet Loss pada area Jaringan Wireless di Lingkungan Fakultas Teknik. Dalam penelitian tindakan yang mendeskripsikan, menginterpretasi dan menjelaskan suatu situasi atau keadaan pada jaringan Wireless LAN dan melakukan analisis hasil perhitungan Downtime jaringan Wireless LAN terhadap perubahan atau intervensi dengan tujuan untuk mengetahui faktor-faktor yang mempengaruhi Reliability, Maintainability dan Availability pada jaringan Wireless LAN sehingga dapat memberikan network service yang lebih baik lagi dengan perbaikan dan pengembangan sistem dan infrastruktur jaringan sehingga dapat meningkatkan kepuasan pengguna suatu layanan jaringan .

Metode yang akan digunakan mengukur kualitas layanan jaringan wireless LAN yaitu QOS terdiri dari parameter Bandwidth, Delay dan Packet Loss dari pengirim ke penerima atau dari ujung ke ujung (end to end) dengan menggunakan simulasi riverbed modeler dengan sistem operasi windows dan RMA (Realibility Maintenance dan availability ) Melihat laju Uptime, Downtime, Good, Failed dilihat dari PRTG. 
Adapun tahapan penelitian yang merupakan bagian dari Action Research ini,

1. Melakukan Diagnosa (Diagnosing)

Rencana tindakan yang akan dilakukan pada tahap ini ditemukan beberapa masalah yang cukup mengganggu kinerja dari jaringan WLAN

2. Melakukan Rencana Tindakan (Action planning)

Memahami pokok masalah yang ada kemudian dilanjutkan dengan menyusun rencana tindakan yang tepat untuk menyelesaikan masalah yang ada, Rencana tindakan yang akan dilakukan dalam penelitian ini yaitu, desain skema jaringan WLAN yang ada saat ini yang akan diimplementasikan pada pengukuran QoS dan RMA.

3. Melakukan Tindakan (Action Taking)

Melakukan pengukuran jaringan dengan model sistem monitoring QoS yang digunakan untuk pengukuran parameter QoS pada jaringan WLAN di Fakultas Teknik

\section{Kerangka Kerja Penelitian}

Kerangka kerja dipakai untuk pedoman langkah-langkah mengerjakan suatu penelitian dengan membuat tahapan metodologi penelitian untuk mengerjakan tesis sehingga tidak terjadi kerancuan selama pengerjaan dan hasil yang akan dicapai menjadi lebih maksimal. Berdasarkan landasan teori yang dikemukakan di atas, kerangka kerja pada penelitian ini dapat dilihat seperti pada gambar di bawah ini.

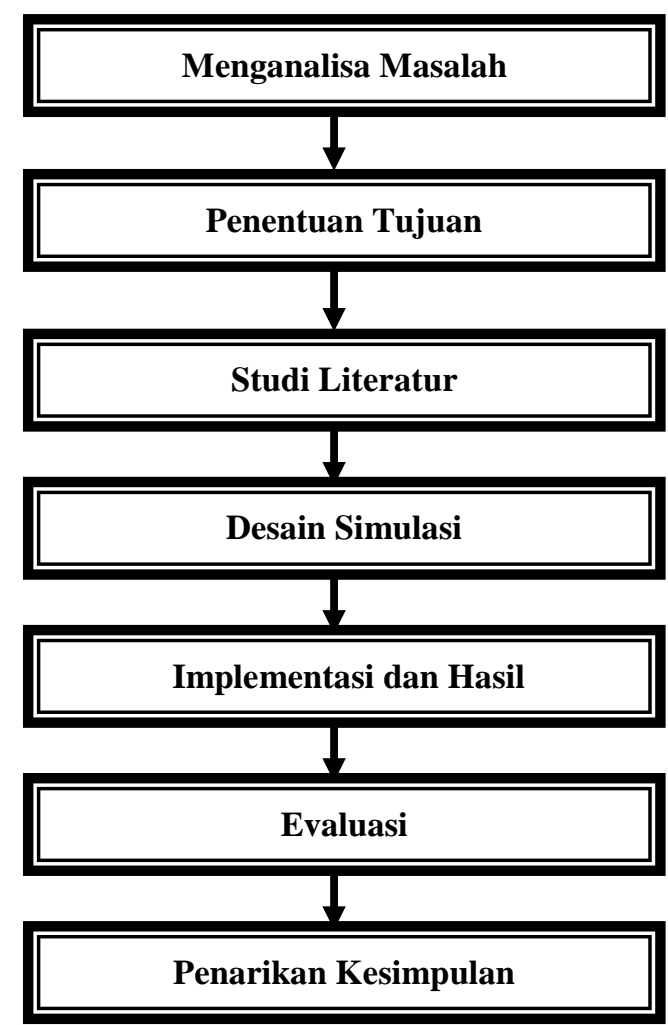

Gambar 2.1 Kerangka Penelitian 


\section{HASIL DAN PEMBAHASAN}

Setelah melakukan percobaan dengan menggunakan Riverbed Modeler wireless LAN 802.11N untuk e learning atas beberapa skenario yang telah disusun seperti di bab IV. Berikut ini adalah hasil simulasi yang ditampilkan dalam bentuk grafik dan pembahasannya.

Menurut Wang, et al. [11], pengkategorian performansi jaringan berdasarkan besarnya delay adalah sebagai berikut :

Tabel 2. Delay

\begin{tabular}{|c|c|}
\hline Kategori Delay & Besar Delay \\
\hline Excellent & $<150 \mathrm{~ms}$ \\
\hline Good & $150 \mathrm{~s} / \mathrm{d} 300 \mathrm{~ms}$ \\
\hline Poor & $300 \mathrm{~s} / \mathrm{d} 450 \mathrm{~ms}$ \\
\hline Unacceptable & $>450 \mathrm{~ms}$ \\
\hline
\end{tabular}

Simulasi juga diukur berdasarkan skenario area jaringan fakultas. Lingkungan simulasi yang model detailnya adalah pengukuran IEEE 802.11n dengan 50 klien dan 100 klien. Peneliti membatasi model simulasi ini berdasarkan area e learning fakultas dan memvalidasi model tersebut dengan pengukuran empiris menggunakan model $e$ learning sederhana dan model-model beban kerja web. Kemudian membuat suatu model berupa sifat browsing pada e-learning dan web klien dan menggunakan model ini pada simulasi yang bertujuan mengukur jaringan e-learning di area suatu fakultas. Eksperimen ini memfokuskan pada angka wireless delay, end to end throughput, wireless delay, dan dampak dari jumlah user serta ukuran objek web e-learning. Faktor-faktor simulasi dirangkum dalam tabel 4.3 sebagai berikut :

Tabel 3. Faktor Simulasi

\begin{tabular}{|c|c|}
\hline Faktor & Levels \\
\hline Jumlah klien & 50,100 \\
\hline $\begin{array}{l}\text { E-Learning } \\
\text { Transfer size }\end{array}$ dan $\quad$ HTTP & $\begin{array}{l}6,5,19,5 \text { dan } \\
39 \mathrm{Mbps}\end{array}$ \\
\hline
\end{tabular}




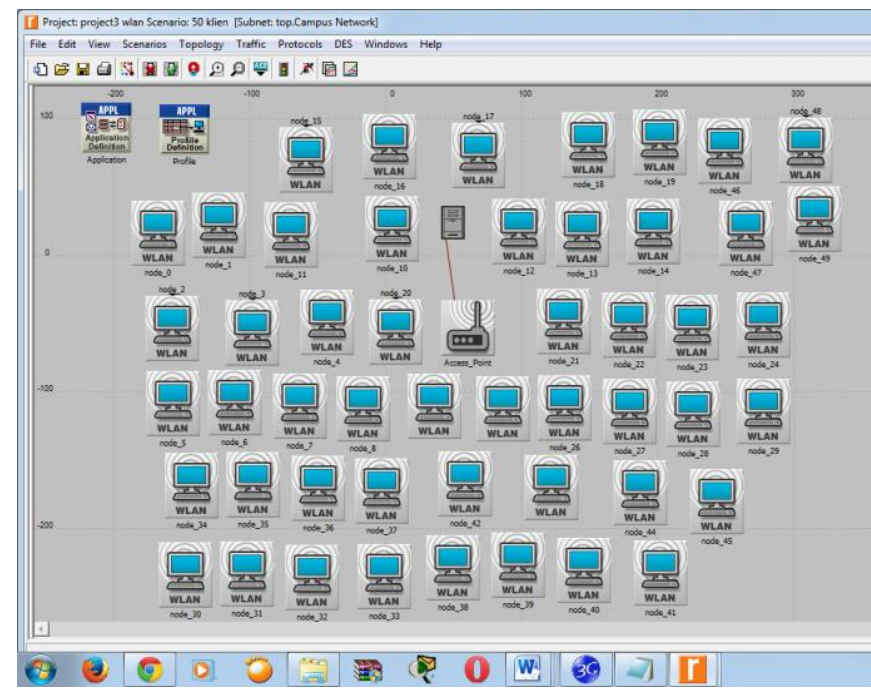

\section{Gambar 3.1 Model Simulasi}

Pada percobaan ini dilakukan untuk melihat apakah ada masalah sharing Wireless LAN sebanyak 50 client. Dalam percobaan ini dibuat beban kerja jaringan yang berbeda. Gambar 3.2 menunjukkan hasil percobaan dengan 50 client.

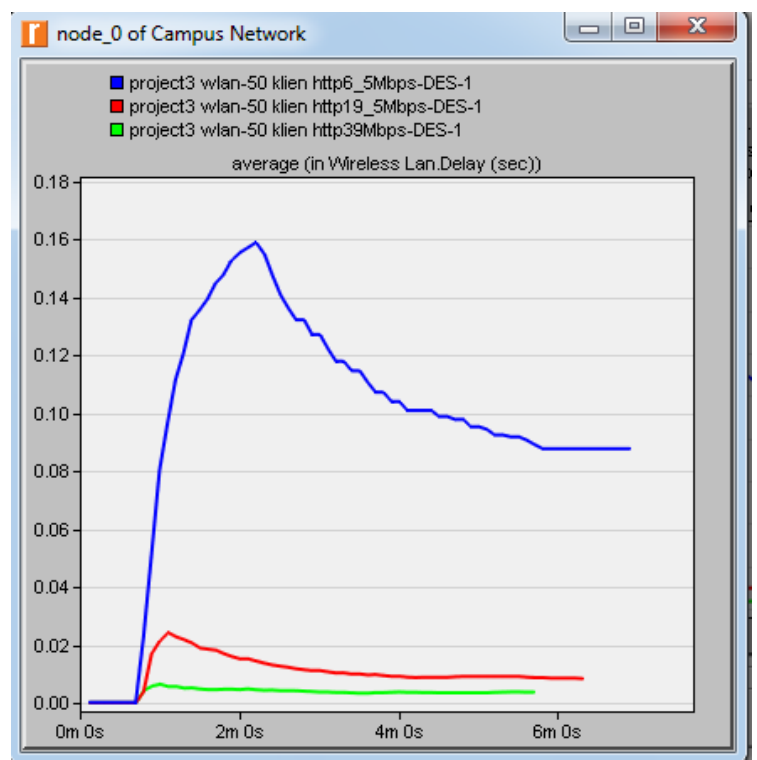

Gambar 3.2 Average Wireless Lan Delay

Dari hasil percobaan di atas dapat di lihat Puncak delay node 0 dengan transfer size 6,5 Mbps : 0.159016764622 detik (159 ms), Puncak delay node 0 dengan transfer size 19,5 Mbps : 0.024255580194 detik (24,2 ms), Puncak delay node 0 dengan transfer size $39 \mathrm{Mb}: 0.006413460225$ detik (6,4 ms). Dari di atas terlihat bahwa delaynya sangat kecil sekali dan termasuk kategori sangat bagus. 


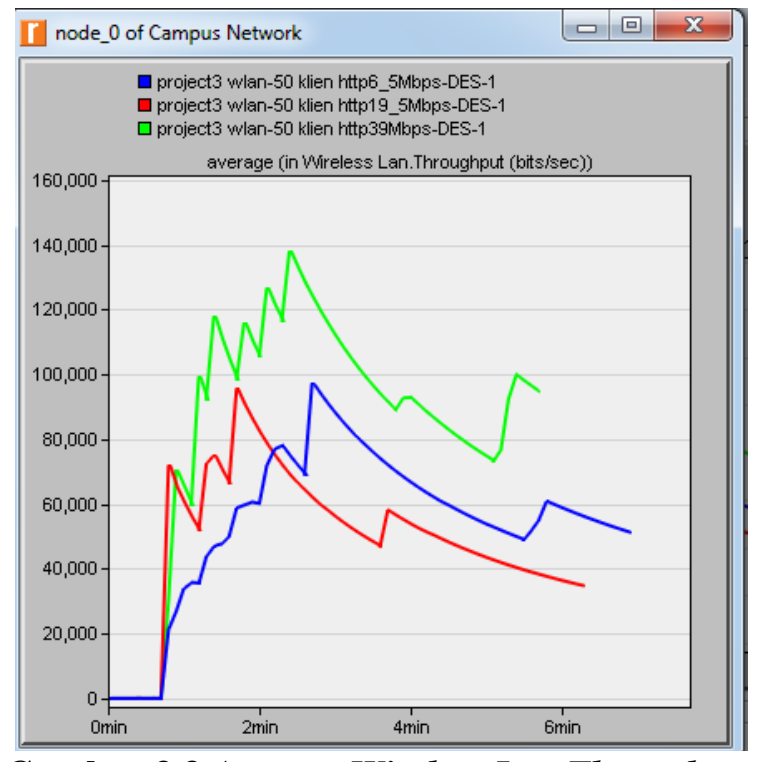

Gambar 3.3 Average Wireless Lan Throughput

Dari hasil percobaan di atas dapat di lihat rata-rata throuhgput node 0 dengan transfer size 6,5 Mbps : 49,79 bit/sec, rata-rata throuhgput node 0 dengan transfer size 19,5 Mbps 48,02 bit/sec, rata-rata throuhgput node 0 dengan transfer size $39 \mathrm{Mbps}$ 71,45 bit/sec.

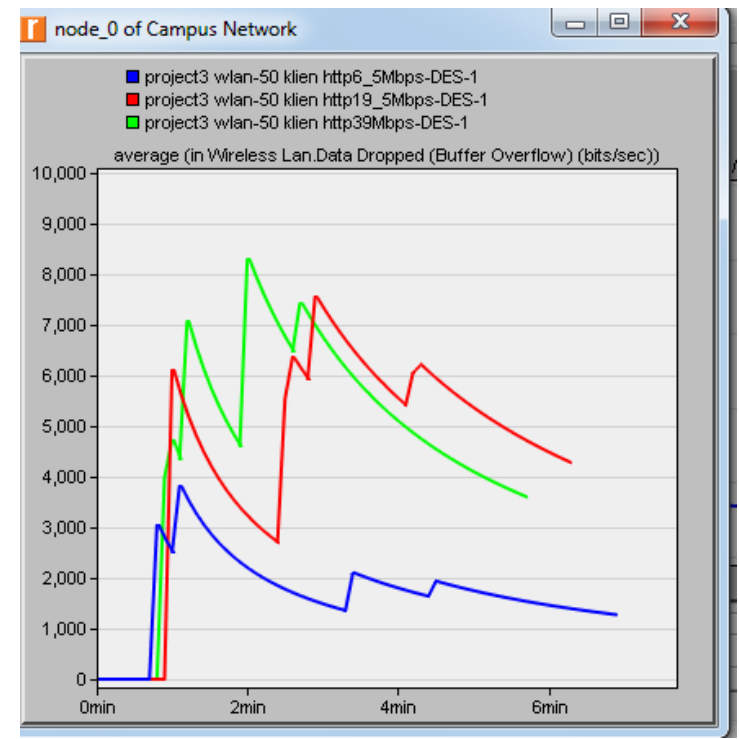

Gambar 3.4 Average Wireless Lan Data Dropped 


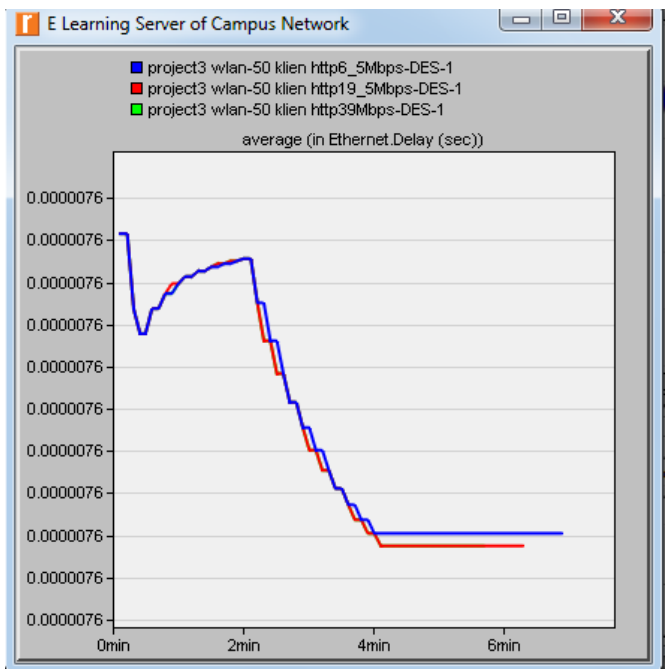

Gambar 3.5 Ethernet delay server

Pada percobaan berikut ini dilakukan untuk melihat apakah ada masalah sharing Wireless LAN sebanyak 100 client. Dalam percobaan ini dibuat beban kerja jaringan yang berbeda. Gambar 3.6 menunjukkan hasil percobaan dengan 100 client

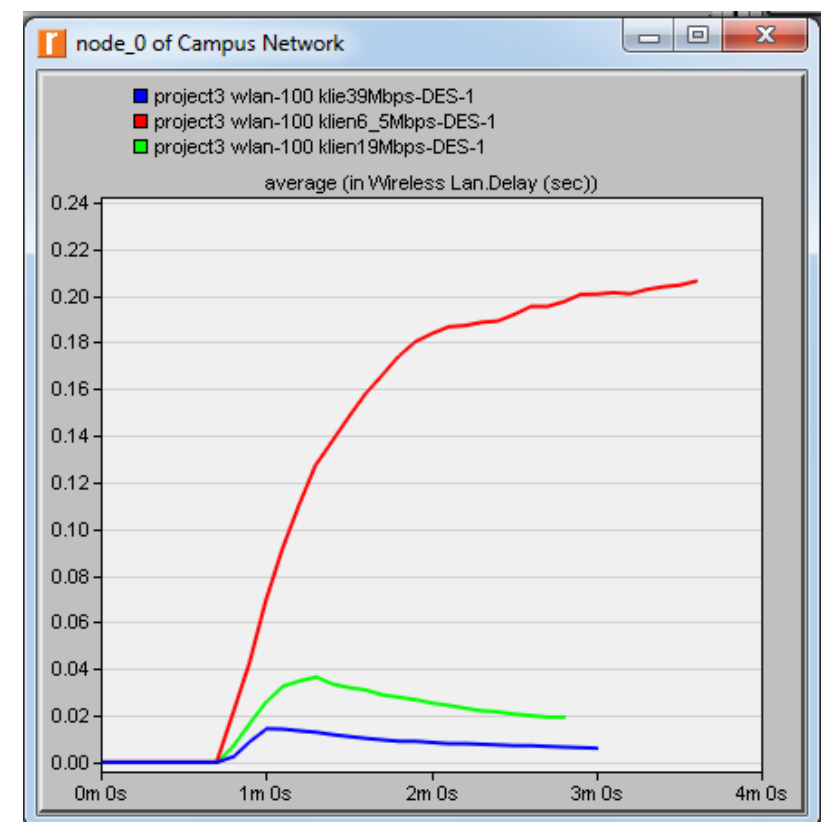

Gambar 3.6 Average Wireless LAN Delay 


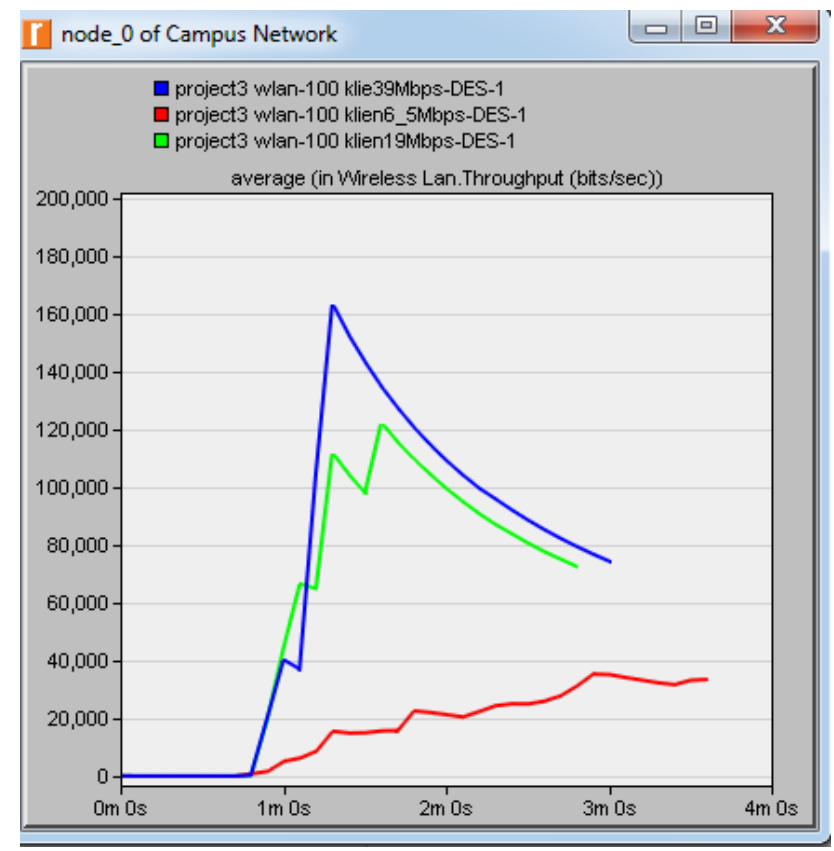

Gambar 3.7 Average Wireless Lan Throuhput

Tabel 4. Hasil Rate

\begin{tabular}{|c|c|c|c|}
\hline \multirow{2}{*}{ Jumlah } & \multicolumn{3}{|c|}{ data rate $(\mathrm{Mb})$} \\
\cline { 2 - 4 } & 6,5 & 19,5 & 39 \\
\hline 50 klien & $160 \mathrm{~ms}$ & $24 \mathrm{~ms}$ & $6,4 \mathrm{~ms}$ \\
\hline 100 klien & $200 \mathrm{~s}$ & $36 \mathrm{~ms}$ & $13 \mathrm{~ms}$ \\
\hline
\end{tabular}

\section{KESIMPULAN}

Hasil simulasi menunjukkan bahwa Wireless LAN IEEE 802.11n dengan mudah dapat mendukung sampai 100 klien yang melakukan browsing akifitas tinggi terhadap web e-learning, penelitian ini berfokus pada perluasan E-Learning dan Web yang ada di suatu fakultas untuk mewakili beban kerja web yang lebih realistis. Sehingga pada penerapan di lapangan memudahkan administrator jaringan dalam merencanakan jaringan e learning di suatu fakultas.

\section{SARAN}

Hasil dari penelitian ini masih belum sempurna, oleh karena itu ada beberapa saran yang mungkin dapat menjadi masukan bagi yang ingin mengembangkan penelitian di bidang ini. Saran untuk pengembangan penelitian yang lain adalah sebagai berikut menggunakan lebih dari satu access point sehingga cakupan wilayah aplikasi ini lebih luas, jumlah klien yang diuji maksimalnya lebih dari klien, dalam penelitian berikutnya dapat lebih dari 100 klien, selain parameter pengukuran delay, throughput dan http page response time mungkin bisa menggunakan packet loss, data dropped dan parameter 
lainnya dan penelitian selanjutnya juga bisa menggunakan netwotk simulator (NS3) dan tipe wireless LAN yang lebih tinggi.

\section{DAFTAR PUSTAKA}

[1] D. E. Hartley, Selling e-learning: American Society for Training and Development, 2006.

[2] G. D. Hantoro, "WiFi (Wireless LAN) Jaringan Komputer Tanpa Kabel," 2009.

[3] O. W. Purbo, P. Tanuhandaru, N. Noertam, and M. R. Djajadikara, "Jaringan Wireless di Dunia Berkembang," Creative Commons Licence, vol. 3, 2007.

[4] E. A. Kadir, A. Siswanto, and A. Syukur, "Performance analysis of wireless LAN $802.11 \mathrm{n}$ standard for e-Learning," in Information and Communication Technology (ICoICT), 2016 4th International Conference on, 2016, pp. 1-6.

[5] A. Ghosh, A. Lasebae, and E. Ever, "Performance evaluation of wireless IEEE 802.11 (b) used for ad-hoc networks in an e-learning classroom network," 2009.

[6] A. S. Tanenbaum, "Computer networks, 4-th edition," ed: Prentice Hall, 2003.

[7] S. A. Najim, I. M. El Emary, and S. M. Saied, "Performance Evaluation of Wireless IEEE 802.11 b used for E-Learning Classroom Network," IAENG International Journal of Computer Science, vol. 34, 2007.

[8] D. L. A. Putra and A. Subhan, "Analisa Kinerja Implementasi Wireless Distribution System Pada Perangkat Access Point 802.11 G Menggunakan OpenWRT," EEPIS Final Project, 2011.

[9] T.-K. Tan and B. Bing, The world wide Wi-Fi: technological trends and business strategies: John Wiley \& Sons, 2004.

[10] E. Tittel, "Schaum's Outline: Computer Networking (Jaringan Komputer)," Jakarta: Erlangga, 2002.

[11] B. Wang, J. Kurose, P. Shenoy, and D. Towsley, "Multimedia streaming via TCP: An analytic performance study," ACM Transactions on Multimedia Computing, Communications, and Applications (TOMM), vol. 4, p. 16, 2008. 